\title{
Low Temperature Sintering of PNN-PZT Ceramics and Its Electrical Properties
}

\author{
이명우 ${ }^{1}$, 김성진 ${ }^{2}$, 윤만순 ${ }^{1}$, 류성림 ${ }^{1}$, 권순용 ${ }^{1, a}$ \\ (Myung-Woo Lee', Sung-Jin Kim², Man-Soon Yoon', Sung-Lim Ryu', and Soon-Yong Kweon ${ }^{1, a}$ )
}

\begin{abstract}
To fabricate a multi-layered piezoelectrics/electrodes structure, the piezoelectrics should be sintered at the temperature lower than $950{ }^{\circ} \mathrm{C}$ to use the silver electrode, which is cheaper than the electrodes containing noble metals such as $\mathrm{Pd}$ and $\mathrm{Pt}$. Therefore, in this study, we modified the composition of $\mathrm{Pb}(\mathrm{Zr}, \mathrm{Ti}) \mathrm{O}_{3}$-based material as $\left(\mathrm{Pb}_{0.98} \mathrm{Cd}_{0.02}\right)\left(\mathrm{Ni}_{1 / 3} \mathrm{Nb}_{2 / 3}\right)_{0.25} \mathrm{Zr}_{0.35} \mathrm{Ti}_{0.4} \mathrm{O}_{3}$ to lower the sintering temperature and to improve the piezoelectric properties. Small amount of $\mathrm{MnCO}_{3}, \mathrm{SiO}_{2}$, and $\mathrm{Pb}_{3} \mathrm{O}_{4}$ were also added to lower the sintering temperature of the ceramic. The prepared raw powders were mixed by using a ball mill for 24 hours. And then the mixed powders were calcinated for 2 hours at $800{ }^{\circ} \mathrm{C}$. The calcinated powders were again crushed with the ball mill for 72 hours. The final powders were pressed for making the shape of $\varnothing 15 \mathrm{~mm}$ disk. The disk-type samples were sintered at temperature range of $850 \sim 950{ }^{\circ} \mathrm{C}$. The crystal phases of the sintered specimens were perovskite structure without secondary phases. All of the measured electrical properties such as electromechanical coupling coefficients $\left(k_{\mathrm{p}}\right)$, mechanical quality factors $\left(\mathrm{Q}_{\mathrm{m}}\right)$, and piezoelectric charge constants $\left(\mathrm{d}_{33}\right)$ were decreased with decreasing the sintering temperatures. The electrical properties measured at the sample sintered at $950{ }^{\circ} \mathrm{C}$ were 54 $\%$ of $\mathrm{k}_{\mathrm{p}}, 503$ of $\mathrm{Q}_{\mathrm{m}}$, and $390 \mathrm{pC} / \mathrm{N}$ of $\mathrm{d}_{33}$, respectively. These properties were considered to be fairly good for the application of multi-layered piezoelectric generators or actuators.
\end{abstract}

Key Words : PNN-PZT ceramic, Piezoelectric properties, Low-temperature sintering, Microstructure

\section{1.서 론}

압전 물질은 기계적인 에너지를 전기적인 에너 지로 변환하는 에너지 변환소재이다. 무기물 및 유 기물을 포함하는 많은 수의 재료가 압전 현상을 일으키는 재료로 알려져 있으며, $\mathrm{Pb}(\mathrm{Zr}, \mathrm{Ti}) \mathrm{O}_{3}$ 와 같 은 대표적인 압전 세라믹스는 현재 실용적인 용도 로 다양하게 적용되고 있는 재료이다[1]. 이러한

1. 충주대학교 신소재공학과/친환경에너지 부품소재센터 (충북 충주시 대학로 72 )

2. (주)제닉슨

a. Corresponding Author : sykweon@cjnu.ac.kr

접수일자 : 2008. 10. 15

1차 심사 : 2008. 11. 12

심사완료 : 2008. 11. 24
압전 세라믹스는 액추에이터, 변압기, 초음파모터, 초음파 소자 및 각종 센서로 응용되고 있으며, 그 응용분야는 크게 증가하고 있다. 최근에는 이러한 응용 분야 중 진동에너지를 수확하여 전기에너지로 활용하는 압전 발전소자 (piezoelectric generator for energy harvesting)에 대한 관심이 커지고 있 으며, 앞으로 도래하는 ubiquitous, 무선 모바일 시 대의 휴대용 전자제품, micro-robotics, MEMS (micro electro-mechanical system) 분야 등의 대 체 에너지원으로 응용하기 위한 연구가 진행되고 있다[2,3]. 특히 인간의 걷기 운동 등과 같은 일상 적인 동작으로 필요한 전력을 얻을 수 있고, 세라 믹 소자를 이용하기 때문에 전자노이즈가 발생되 지 않을 뿐 아니라 반영구적으로 사용할 수가 있 
어서, 기존 이차전지를 대체 또는 보완 할 수 있는 기술로 그 기대가 크다.

PZT계 세라믹스는 높은 유전상수와 우수한 압 전특성으로 전자세라믹스 분야에서 가장 널리 사 용되어지고 있지만 $1200{ }^{\circ} \mathrm{C}$ 이상의 높은 소결온도 때문에 $1000{ }^{\circ} \mathrm{C}$ 부근에서 급격히 휘발되는 $\mathrm{PbO}$ 로 인한 환경오염과 기본조성의 변화로 인한 압전 특 성의 저하가 문제시 되고 있다[4]. 또한, MLCC (multi-layer ceramic capacitor) 등의 적층 세라믹 스의 제작 시 구조적 특성상 내부전극이 도포된 상태에서 동시 소결이 필요한데, 융점이 낮은 $\mathrm{Ag}$ 전극 대신 값비싼 $\mathrm{Pd}$ 나 $\mathrm{Pt}$ 가 다량 함유된 $\mathrm{Ag} / \mathrm{Pd}$, $\mathrm{Ag} / \mathrm{Pt}$ 전극이 사용되고 있어 경제성이 떨어지는 단점을 갖게 된다[4-6]. 순수 $\mathrm{Ag}$ 전극을 사용하거 나 $\mathrm{Ag}$ 의 비율이 높은 내부전극을 사용하기 위해서 는 $950{ }^{\circ} \mathrm{C}$ 이하에서 소결되고 우수한 전기적 특성 을 갖는 압전세라믹스를 개발 하는 것이 필요하다.

PZT 소재가 발견된 이후 PZT 세라믹스는 주로 2성분계로 만들어졌는데, 2성분계 $\mathrm{PZT}$ 는 상경계 영역 (MPB: morphotropic phase boundary)이 좁 기 때문에 조성 변화에 의한 특성 개선에 한계가 있었다[1]. 따라서 PZT 세라믹스에 1성분을 추가 한 3성분계에 대한 연구가 활발히 진행되어 왔다 [1,4-6]. 특히 PZT 세라믹스에 $\mathrm{Pb}\left(\mathrm{Ni}_{1 / 3} \mathrm{Nb}_{2 / 3}\right) \mathrm{O}_{3}$ 를 고용시켜 제조하는 $\mathrm{Pb}\left(\mathrm{Ni}_{1 / 3} \mathrm{Nb}_{2 / 3}\right) \mathrm{O}_{3}-\mathrm{PbZrO}_{3}$ $\mathrm{PbTiO}_{3}$ 세라믹스는 실온에서 전기기계결합계수 $\left(\mathrm{k}_{\mathrm{p}}\right)$ 및 비유전율 $\left(\varepsilon_{\mathrm{r}}\right)$ 이 크기 때문에 액츄에이터용 재료로 주목을 받아왔다[7].

본 연구에서는 전기기계결합계수 특성이 우수한 $\mathrm{Pb}\left(\mathrm{Ni}_{1 / 3} / \mathrm{Nb}_{2 / 3}\right)-\mathrm{Pb}(\mathrm{Zr}, \mathrm{Ti}) \mathrm{O}_{3}$ (이하 $\mathrm{PNN}-\mathrm{PZT}$ 라 함) 압전세라믹의 조성을 선행 연구 조사 및 보완 실 험을 통하여 설계한 다음, 이 PNN-PZT 세라믹의 소결공정 수행에 있어서 $\mathrm{MnCO}_{3}, \mathrm{SiO}_{2}, \mathrm{~Pb}_{3} \mathrm{O}_{4}$ 등을 공정 (eutectic) 조성을 갖도록 소량 첨가하여 액상 소결 특성을 부여하여 소결 온도를 감소시키려는 시도를 하였다[8].

\section{2. 실 험}

그림 1은 본 연구에서 선택한 PNN-PZT 3성분 계 세라믹스의 기본 상태도 및 실험에 적용한 조 성의 영역 (그림의 빗금 친 부분)을 나타내고 있다 [8]. 일반적으로 PZT계 세라믹에서는 상경계 영역 에서 가장 우수한 전기적 특성을 보인다. 따라서

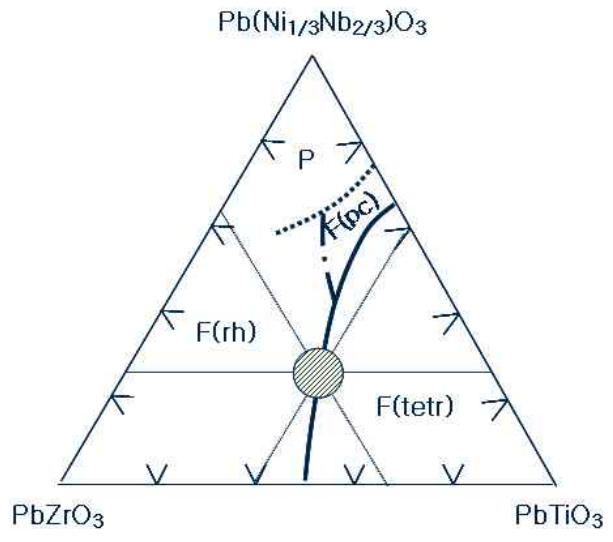

그림 1. PNN-PZT 3성분계 세라믹스의 상태도.

Fig. 1. Phase diagram of PNN-PZT ceramics.

본 연구에서도 다음과 같은 상경계 영역의 조성에 서 소결온도 변화에 따른 미세구조 분석 및 전기 적 특성을 평가하였다: $\left(\mathrm{Pb}_{0.98} \mathrm{Cd}_{0.02}\right)\left(\mathrm{Ni}_{1 / 3} / \mathrm{Nb}_{2 / 3}\right)_{0.25}$ $\mathrm{Zr}_{0.35} \mathrm{Ti}_{0.4} \mathrm{O}_{3}+\mathrm{MnCO}_{3}(0.5 \mathrm{wt} \%)+\mathrm{SiO}_{2}(0.45$ $\mathrm{wt} \%)+\mathrm{Pb}_{3} \mathrm{O}_{4}(1 \mathrm{wt} \%)$. 여기에서 $\mathrm{Pb}$ 대신 약간 의 $\mathrm{Cd}$ 으로 치환한 것과 $\mathrm{MnCO}_{3}(0.5 \mathrm{wt} \%)+\mathrm{SiO}_{2}$ $(0.45 \mathrm{wt} \%)+\mathrm{Pb}_{3} \mathrm{O}_{4}(1 \mathrm{wt} \%)$ 를 첨가한 것은 액상 소결 특성을 부여하여 저온 소결 특성을 향상시키 고자 한 것이다.

조성에 따라 원료 분말을 $0.01 \mathrm{~g}$ 까지 칭량하고, 알코올 용액에 원료 분말과 지르코니아 볼을 함께 넣은 다음 24 시간 동안 1 차 볼밀을 하여 원료 분 말들을 혼합하였다. 최종 소결체에서 파이로클로어 (pyrochlore) 상의 형성을 억제하여 안정된 페로브 스카이트 상을 형성시키기 위하여 $\mathrm{NiNb}_{2} \mathrm{O}_{6}$ 를 미리 상 합성을 하였고[7], 혼합된 분말을 $800{ }^{\circ} \mathrm{C}$ 에서 2 시간동안 하소하는 2 단계 하소 공법을 적용하였다. 하소한 분말을 72 시간동안 볼밀 하여 최종 분말을 얻었다. 최종 분말에 $\mathrm{PVB}$ ( $1 \mathrm{wt} \%$ 수용액)를 첨가 하여 1 축 프레스를 이용하여 $1 \mathrm{kgf} / \mathrm{cm}^{2}$ 압력을 가 하여 $\Phi 15$ 원판 형태로 성형하였다. 그 다음 650 ${ }^{\circ} \mathrm{C}$ 에서 2 시간 동안 가열하는 탈지공정을 수행하고, $875{ }^{\circ} \mathrm{C} \sim 950{ }^{\circ} \mathrm{C}$ 온도 범위에서 소결 온도를 변화 시키면서 2 시간동안 소결 공정을 진행하였다. 전극 형성 전에 소결체의 밀도 측정, 주사전자현미경 (SEM: S-2400, Hitachi Co., Japan)을 이용한 미세 구조 분석 및 $\mathrm{X}$-선 회절기 (XRD: Rigaku Co., Japan)를 이용한 결정구조 분석 등을 수행하였다. 그 다음, 전기적 특성을 평가하기 위하여 두께 1 $\mathrm{mm}$ 로 연마한 시편에 은 $(\mathrm{Ag})$ 전극을 도포하여 $650{ }^{\circ} \mathrm{C}$ 에서 20 분 동안 열처리하여 전극을 형성하 
였다. 전극 공정 이후에는 $150{ }^{\circ} \mathrm{C}$ 실리콘유에서 3 $\mathrm{kV} / \mathrm{mm}$ 의 전계를 가해 30 분간 분극 처리를 수행하 였다. 압전 전하상수는 압전 전하상수 측정기 $\left(\mathrm{d}_{33}-\right.$ meter: APC-8000)를 이용하여 측정하였고, 비유전율, 전기기계결합계수 및 기계적품질계수 등은 임피던스 분석기 (impedance/gain phase analyzer: HP4194A) 를 이용하여 특성을 측정 하였다. 또한 전압-분극 특성의 평가에는 강유전 특성 측정기 (ferroelectric tester: Precision-LC, Radiant Technologies, USA) 를 이용하였다.

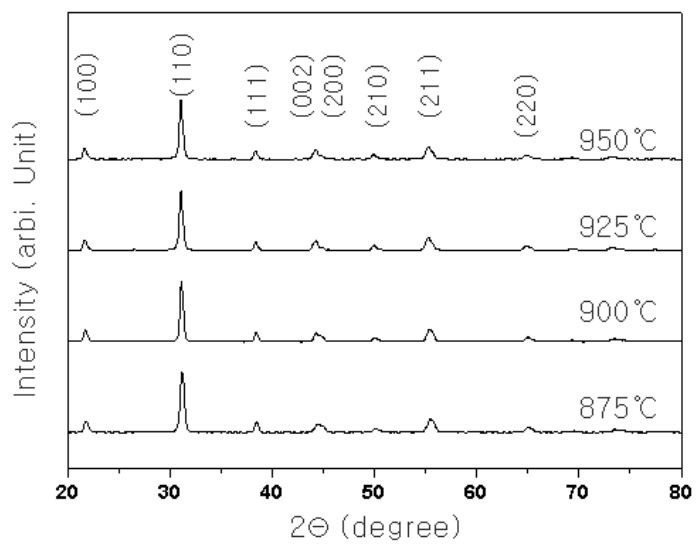

그림 2. $\mathrm{PNN}-\mathrm{PZT}$ 세라믹의 소결 온도에 따른 $\mathrm{XRD}$ 회절 도형.

Fig. 2. X-ray diffraction patterns of the $\mathrm{PNN}^{-}$ PZT ceramics sintered at various temperatures.

\section{3. 결과 및 고찰}

그림 2는 소결온도에 따른 $\mathrm{PNN}-\mathrm{PZT}$ 세라믹의 $\mathrm{X}$-선 회절 패턴을 나타낸 것 이다. 모든 시편에서 이차상이 없는 순수한 페로브스카이트 구조를 나 타냈다. $950{ }^{\circ} \mathrm{C}$ 에서 소결한 $\mathrm{PNN}-\mathrm{PZT}$ 세라믹의 $\mathrm{XRD}$ 회절 도형에서 (X-선원: $\mathrm{Cu} \mathrm{Ka}$ 선) 43도와 46도 사이를 정밀 측정해 보면, (002)면의 회절선 (2Ө)은 44.3도이고, (200)면의 회절선은 44.8도로 측정되었다. 이러한 실험 결과로부터 격자상수와 이론밀도를 계산할 수 있는데, 계산한 $\mathrm{PNN}-\mathrm{PZT}$ 의 이론 밀도는 약 $8.1 \mathrm{~g} / \mathrm{cm}^{3}$ 이었고, 정방정도 (tetragonality: $\mathrm{T}=\mathrm{c} / \mathrm{a}$ )는 약 1.012 ( $\mathrm{c}=4.0902 \AA$, $\mathrm{a}=4.0462 \AA)$ 로 계산되었다.

그림 3 은 소결온도에 따른 $\mathrm{PNN}-\mathrm{PZT}$ 소결체의 소결 밀도를 나타낸 것이다. 소결체의 밀도는 Archimedes 법 (ASTM C373-71)을 적용하여 측

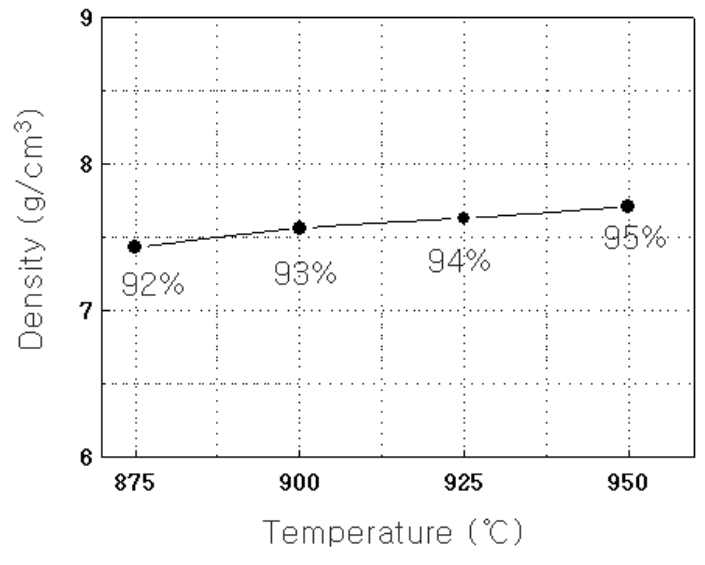

그림 3. PNN-PZT 세라믹의 소결 온도에 따른 소결 밀도의 변화.

Fig. 3. Density of the PNN-PZT ceramics as a function of sintering temperature.

정하였다[9]. $\mathrm{XRD}$ 회절 실험 결과로부터 계산한 이론 밀도 값인 $8.1 \mathrm{~g} / \mathrm{cm}^{3}$ 을 적용하면, $950{ }^{\circ} \mathrm{C}$ 에서 소결한 $\mathrm{PNN}-\mathrm{PZT}$ 벌크 세라믹의 상대 밀도는 약 $95 \%$ 정도의 양호한 값을 보였다. 그러나 소결 온 도가 낮아짐에 따라서 상대 밀도 값은 점점 낮아 지는 경향을 확인할 수 있었다.
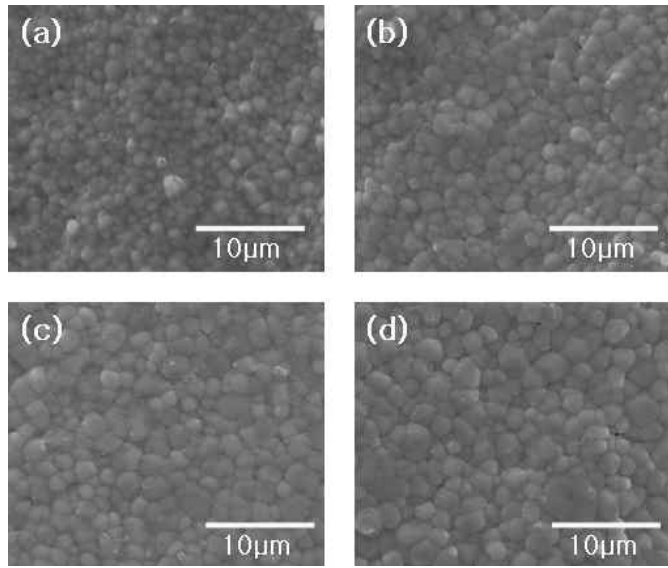

그림 4. PNN-PZT 세라믹의 소결 온도에 따른 미세구조의 변화: (a) $875{ }^{\circ} \mathrm{C}$, (b) $900{ }^{\circ} \mathrm{C}$, (c) $925{ }^{\circ} \mathrm{C}$, (d) $950{ }^{\circ} \mathrm{C}$.

Fig. 4. Microstructures of the PNN-PZT ceramics as a function of sintering temperature: (a) $875{ }^{\circ} \mathrm{C}$, (b) $900{ }^{\circ} \mathrm{C}$, (c) $925{ }^{\circ} \mathrm{C}$, (d) $950{ }^{\circ} \mathrm{C}$. 
그림 4는 소결 후에 PNN-PZT 세라믹의 표면 에서 관찰한 주사전자현미경 ( $\mathrm{SEM}$ ) 사진이다. 모 든 시편에서 기공들은 거의 관찰되지 않는 양호한 소결체를 형성함을 알 수 있었다. 또한 그림에서 볼 수 있듯이, 소결 온도가 증가함에 따라서 입자 (grain) 들의 크기는 점점 증가하였는데, 이러한 결과로부터 소결 온도가 높아짐에 따라서 소결체의 치밀화 및 입자 성장이 활발히 진행됨을 유추할 수 있다. 입자 크기가 가장 큰 $950{ }^{\circ} \mathrm{C}$ 에서 소결한 시편의 입자 크기는 대략 $1 \sim 3 \mu \mathrm{m}$ 정도의 크기를 보이고 있다.

그림 5는 소결 온도 변화에 따른 PNN-PZT 소 결체의 전계-분극 곡선의 변화를 보여주고 있다. 강유전체 특성 측정기에서, 두께 $1 \mathrm{~mm}$ 의 벌크 압 전세라믹에 인가한 최대 전압은 $3.5 \mathrm{kV}$ 이었다. 소결 온도가 증가함에 따라서 잔류분극 (Pr: remanent polarization) 값은 다소 증가하지만 $875{ }^{\circ} \mathrm{C}$ 에서 소 결한 시편에서도 $2 \mathrm{Pr}$ 이 대략 $20 \mu \mathrm{\mu} / \mathrm{cm}^{2}$ 정도의 양호한 강유전 특성을 보이고 있음을 확인할 수 있었다. $950{ }^{\circ} \mathrm{C}$ 에서 소결한 시편에서 가장 높은 잔류 분극 값을 보이고 있는데, $2 \mathrm{Pr}$ 이 대략 $26 \mu \mathrm{C} / \mathrm{cm}^{2}$ 정도의 우수한 강유전성을 보였다.
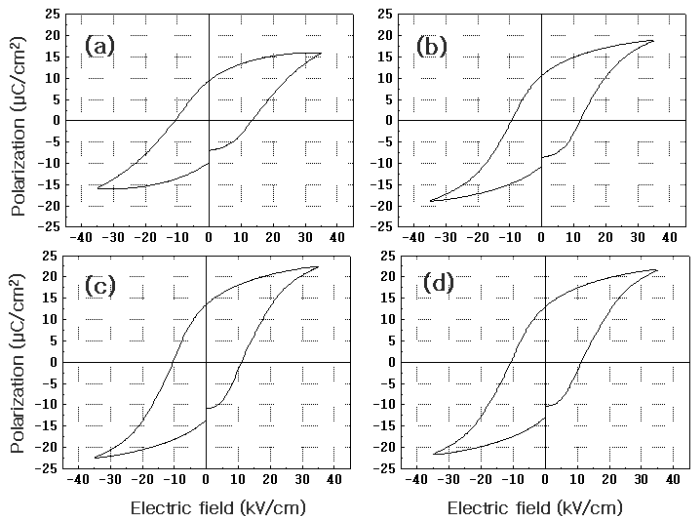

그림 5. $\mathrm{PNN}-\mathrm{PZT}$ 세라믹의 소결 온도에 따른 전계-분극 곡선의 변화: (a) $875{ }^{\circ} \mathrm{C}$, (b) $900{ }^{\circ} \mathrm{C}$, (c) $925{ }^{\circ} \mathrm{C}$, (d) $950{ }^{\circ} \mathrm{C}$.

Fig. 5. Electric field vs. polarization curves of the PNN-PZT ceramics as a function of sintering temperature: (a) $875{ }^{\circ} \mathrm{C}$, (b) $900{ }^{\circ} \mathrm{C}$, (c) $925{ }^{\circ} \mathrm{C}$, (d) $950{ }^{\circ} \mathrm{C}$.

그림 6 은 소결 온도에 따른 비유전율 $\left(\varepsilon_{\mathrm{r}}\right)$ 의 변 화를 보여주고 있다. 비유전율 역시 소결 온도가
높아짐에 따라서 증가하는 경향을 보였다. 이러한 현상은 그림 5 의 분극 값 증가 경향과 잘 일치함 을 알 수 있다.

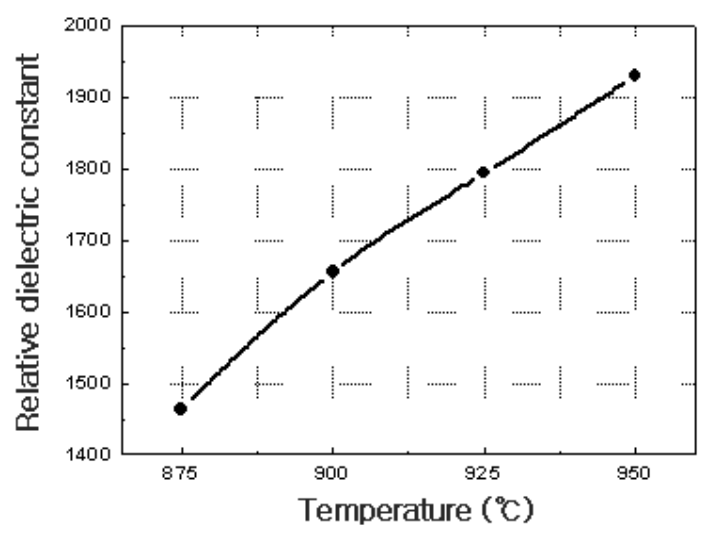

그림 6. PNN-PZT 세라믹의 소결 온도에 따른 비유전율 $\left(\varepsilon_{\mathrm{r}}\right)$ 의 변화.

Fig. 6. The variation of relative dielectric constant measured in the PNN-PZT ceramics sintered at various temperature.

그림 7은 임피던스 분석기 (HP4194A)로 측정한 임피던스 스펙트럼 데이터를 이용하여 공진-반공 진 법을 적용하여 계산한 $\mathrm{PNN}-\mathrm{PZT}$ 세라믹 소결 체의 전기기계결합계수 $\left(\mathrm{k}_{\mathrm{p}}\right)$ 및 기계적품질계수 $\left(\mathrm{Q}_{\mathrm{m}}\right)$ 의 변화를 보여주고 있다[10]. 소결 온도가 증 가함에 따라서 기계적품질계수 및 전기기계결합계 수는 모두 증가하는 경향을 보이고 있다. 즉, 950 ${ }^{\circ} \mathrm{C}$ 에서 소결한 시편에서 최대값을 보이고 있는데, 이때의 값은 각각 $54 \%\left(\mathrm{k}_{\mathrm{p}}\right)$ 및 $503\left(\mathrm{Q}_{\mathrm{m}}\right)$ 으로 상 당히 우수한 특성을 나타내었다.

그림 8은 $\mathrm{PNN}-\mathrm{PZT}$ 세라믹의 소결 온도에 따 른 압전전하상수 $\left(\mathrm{d}_{33}\right)$ 및 압전전압상수 $\left(\mathrm{g}_{33}\right)$ 의 변화를 보여주고 있다. 압전전하상수는 압전전하상 수 측정기 $\left(\mathrm{d}_{33}\right.$-meter: $\left.\mathrm{APC}-8000\right)$ 를 이용하여 측 정하였고, 압전전압상수는 다음과 같은 식으로 계 산하였다.

$$
g_{33}=d_{33} / \epsilon_{r}
$$

여기에서 $\varepsilon_{\mathrm{r}}$ 은 그림 6 에 나타낸 비유전율이다. 압 전전하상수는 소결 온도가 증가함에 따라서 거의 직선적으로 증가하는 경향을 보이지만, 압전전압상 수는 $900{ }^{\circ} \mathrm{C}$ 이상의 소결온도에서는 거의 변화가 


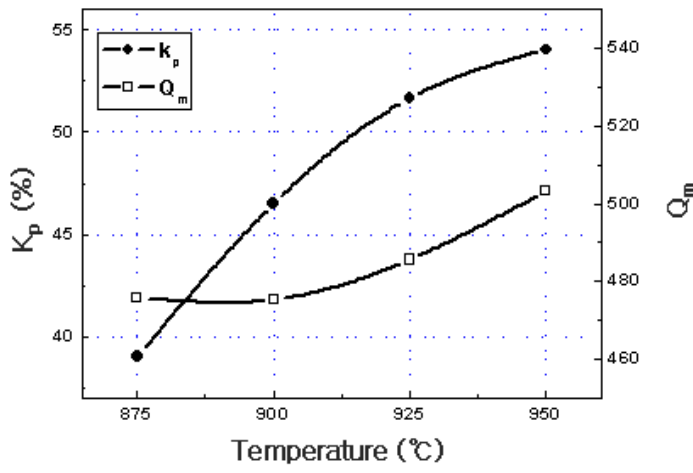

그림 7. $\mathrm{PNN}-\mathrm{PZT}$ 세라믹의 소결 온도에 따른 전기기계결합계수 $\left(\mathrm{k}_{\mathrm{p}}\right)$ 및 기계적품질계수 $\left(\mathrm{Q}_{\mathrm{m}}\right)$ 의 변화.

Fig. 7. The variations of both electromechanical coupling factor $\left(\mathrm{k}_{\mathrm{p}}\right)$ and mechanical quality factor $\left(\mathrm{Q}_{\mathrm{m}}\right)$ measured in the PNN-PZT ceramics sintered at various temperature.

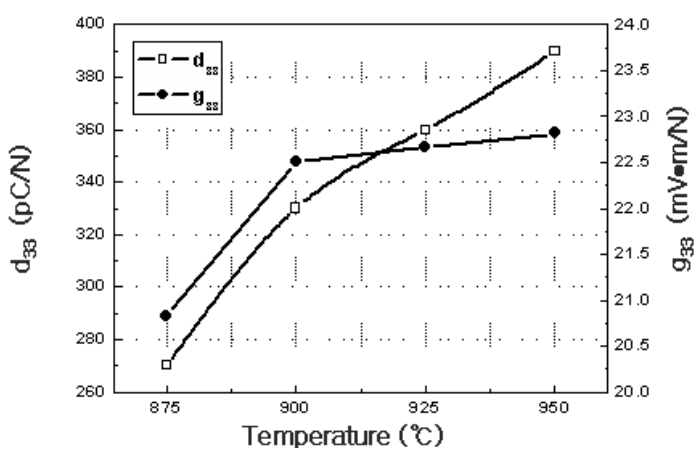

그림 8. $\mathrm{PNN}-\mathrm{PZT}$ 세라믹의 소결 온도에 따른 압전전하상수 $\left(\mathrm{d}_{33}\right)$ 및 압전전압상수 $\left(\mathrm{g}_{33}\right)$ 의 변화.

Fig. 8. The variations of both piezoelectric charge constant $\left(\mathrm{d}_{33}\right)$ and piezoelectric voltage constant $\left(\mathrm{g}_{33}\right)$ measured in the PNN-PZT ceramics sintered at various temperature.

없음을 확인할 수 있었다. 가장 높은 값을 보이고 있는 $950{ }^{\circ} \mathrm{C}$ 소결체에서의 압전전하상수 및 압전 전압상수는 각각 $390 \mathrm{pC} / \mathrm{N}\left(\mathrm{d}_{33}\right)$ 및 $22.8 \mathrm{mV} \cdot \mathrm{m} / \mathrm{N}$ $\left(\mathrm{g}_{33}\right)$ 으로 상당히 우수한 특성을 나타내었다.
이상의 실험 결과를 종합해 보면, 모든 전기적 특성이 소결 온도가 증가함에 따라서 증가하는 경 향을 보이고 있다. 전자현미경을 이용한 미세구조 분석 결과에서는 소결온도 증가에 따라 입자 크기 가 증가하는 것으로 나타났고, 소결밀도는 소결온 도가 증가할수록 증가하는 경향을 보였다. 따라서 소결온도 증가에 따른 전기적 특성 향상은 시편의 상대밀도 증가에 따른 현상으로 설명될 수 있다.

\section{4. 결 론}

본 연구는 전극과 세라믹의 동시 소성이 가능한 적층형 압전 발전기를 개발하기 위하여, 압전 특성 이 우수한 PNN-PZT 세라믹의 저온 소결 특성 및 이때의 전기적 특성을 평가하였다. $875{ }^{\circ} \mathrm{C} \sim 950{ }^{\circ} \mathrm{C}$ 온도 범위에서 소결온도에 따른 미세구조를 분석 한 결과, 소결 온도에 관계없이 모든 소결체는 기 공이 거의 관찰되지 않는 치밀한 미세구조를 보였 고, 이차상이 없는 순수한 페로브스카이트 구조를 나타냈다. PNN-PZT 세라믹 소결체의 전기기계결 합계수, 기계적품질계수 및 압전전하상수 등의 전 기적 특성은 소결 온도가 증가함에 따라서 모두 증가하는 경향을 보였는데, 이러한 현상은 온도 증 가에 따른 밀도 증가로 설명할 수 있었다. $950{ }^{\circ} \mathrm{C}$ 에서 소결한 시편에서 측정한 전기적 특성 값들은 각각 $54 \%\left(\mathrm{k}_{\mathrm{p}}\right), 503\left(\mathrm{Q}_{\mathrm{m}}\right)$ 및 $390 \mathrm{pC} / \mathrm{N}\left(\mathrm{d}_{33}\right)$ 으로 상당히 양호한 특성을 나타내었다. 이상의 실험 결 과들을 종합해 보면, $950{ }^{\circ} \mathrm{C}$ 이하의 소결체에서도 상당히 양호한 전기적 특성을 보이고 있어서, 본 연구의 저온 소결용 $\mathrm{PNN}-\mathrm{PZT}$ 압전세라믹스는 적 층형 압전 발전 소자 제작 등에 적용이 충분히 가 능할 것으로 판단되었다.

\section{감사의 글}

본 연구는 지식경제부의 지역혁신센터사업 (RIC), 충북지역산업기술개발사업의 지원을 받아 수행하 였습니다.

\section{참고 문헌}

[1] Y. Xu, "Ferroelectric Materials and Their Application", Elsevier Science, Amsterdam, 1991. 
[2] J. Kymissis, C. Kendall, J. Paradiso, and N. Gershenfeld, "Parasitic power harvesting in shoes", in IEEE Intl. Symp. on Wearable Computers, p. 132, 1998.

[3] 정대용, 송현철, 윤석진, "Piezoelectric energy harvesting", 전기전자재료, 20권, 12 호, p. 45, 2007.

[4] T. Hayashi, J. Tomizawa, T. Hasegawa, and Y. Akiyama, "Low-temperature fabrication of $\mathrm{Pb}\left(\mathrm{Ni}_{1 / 3} \mathrm{Nb}_{2 / 3}\right) \mathrm{O}_{3}-\mathrm{Pb}\left(\mathrm{Zr}_{0.3} \mathrm{Ti}_{0.7}\right) \mathrm{O}_{3}$ ceramics with $\mathrm{LiBiO}_{2}$ as a sintering aid", J. Europ. Ceram. Soc., Vol. 24, p. 1037, 2004

[5] 권정호, 최문석, 이대수, 정연학, 김일원, 송재 성, 정순종, 이재신, " $\mathrm{Y}$ 치환에 따른 $\mathrm{Pb}\left(\mathrm{Ni}_{1 / 3}\right.$ $\left.\mathrm{Nb}_{2 / 3}\right) \mathrm{O}_{3}-\mathrm{PbZrO}_{3}-\mathrm{PbTiO}_{3}$ 세라믹의 압전특성 및 적층형 압전 액츄에이터 응용”, 전기전자 재료학회논문지, 17권, 2호, p. 184, 2004.

[6] 류주현, 이갑수, 이일하, “순수한 $\mathrm{Ag}$ 내부전극 을 사용한 $\mathrm{PZW}-\mathrm{PMN}-\mathrm{PZT}$ 저손실 적측 액
츄에이터의 적층수에 따른 압전 특성", 전기 전자재료학회논문지, 21권, 6호, p. 524, 2008.

[7] 이기태, 남효덕, "PNN-PT-PZ계 압전세라믹 스의 전기적 특성에 미치는 Pyrochlore 상의 영향”, 요업학회지, 31권, 9호, p. 1030, 1994.

[8] K.-H. Hellwege and A. M. Hellwege, "Numerical Data and Functional Relationships in Science and Technology: Ferroelectrics and Related Substances", Springer-Verlag, Berlin-Heidelberg, p. 476, 1981.

[9] Standard test method for water absorption, bulk density, apparent porosity, and apparent specific gravity for fired whiteware products, ASTM C373-72, 1994.

[10] IRE Standard Committee, "Standard on Piezoelectric Crystals: Determination on Elastic, Piezoelectric, and Dielectric Constants - Electromechanical Coupling factor", Proc. of the IRE, p. 764, 1958. 